Manuelito M. Reyes, MD'

Rosario R. Ricalde, $M^{1}$

Jennifer B. Tanalgo, MD²

Concepcion J. Baldoz MD²

'Department of Otorhinolaryngology

Head and Neck Surgery

Quirino Memorial Medical Center

${ }^{2}$ Department of Medical Imaging

Quirino Memorial Medical Center
Correspondence: Dr. Manuelito M. Reyes Department of Otorhinolaryngology

Head and Neck Surgery

Quirino Memorial Medical Center

Katipunan Road Ext., Project 4, Quezon City 1108

Philippines

Phone: (632) 4212250 local 117

Email: docnoelreyes@yahoo.com

Reprints will not be available from the author.

The authors declared that this represents original material that is not being considered for publication or has not been published or accepted for publication elsewhere, in full or in part, in print or electronic media; that the manuscript has been read and approved by all the authors, that the requirements for authorship have been met by each author, and that each author believes that the manuscript represents honest work.

Disclosures: The authors signed disclosures that there are no financial or other (including personal) relationships, intellectual passion, political or religious beliefs, and institutional affiliations that might lead to a conflict of interest.

\title{
Prevertebral Soft Tissue Thickness Among Pediatric Patients
}

\begin{abstract}
Objectives: This study aimed to determine the prevertebral soft tissue thickness among normal patients aged 0-14 years old in a tertiary government training hospital, to compare these values with divergent criteria in the standard otorhinolaryngology and radiology texts used in our institution, and to recommend adoption of a set of criteria based on the results.
\end{abstract}

ABSTRACT

\section{Methods:}

Design: Descriptive Study

Setting: Tertiary Government Hospital

Subjects and Methods: Lateral cervical radiographs taken from May 2007 to August 2009 which were initially read as normal were collected. Fifty (50) patients, 39 males and 11 females, aged 0-14 years old meeting inclusion criteria were reviewed and prevertebral soft tissue thicknesses (PVST) and cervical vertebral body diameter at levels C2, C5, C6 were measured and compared to criteria set by standard otorhinolaryngology and radiology textbooks.

Results: The average PVST at C2 ranged from $4.02 \mathrm{~mm}$ for $2-3$ year-olds $(\mathrm{n}=2)$ to $8.16 \mathrm{~mm}$ for 1 -2 year-olds $(n=2)$. The average PVST at $C 5$ ranged from $8.11 \mathrm{~mm}$ for $1-2$ year-olds to $10.75 \mathrm{~mm}$ for for 0-1 year-olds. The average PVST at C6 ranged from $7.13 \mathrm{~mm}$ for $1-2$ year-olds to 10.36 $\mathrm{mm}$ for $0-1$ year-olds. Only $12 \%$ of the patients satisfied the criteria set by Keats and Lusted, while $100 \%$ satisfied Duncan's criteria, $94 \%$ and $98 \%$ satisfied Wippold's first and second criteria respectively.

Conclusion: All of the PVST criteria mentioned in Cummings' Textbook of Otorhinolaryngology Head and Neck Surgery had a more than $90 \%$ accuracy compared to only $12 \%$ for those mentioned in Keats and Lusted's Atlas of Roentgenographic Measurement. Therefore, we recommend the use of any criteria for PVST contained in the former over the latter.

\section{Keywords: prevertebral soft tissue thickness, cervical vertebra}

Prevertebral soft tissue thickness (PVST) evaluation using soft tissue lateral neck $x$-rays is an important tool for otorhinolaryngologists in the diagnosis and management of pathologies involving the deep neck spaces particularly deep neck infections (DNI). Despite recent advancements in antibiotics, DNI's remain associated with severe illness and death, especially among children. 
The assessment of the PVST is critical especially when any pathologic condition involving the PVST poses danger of obstructing the airway warranting tracheostomy tube insertion or any other life saving intervention. At our institution's Department of Medical Imaging, the PVSTs of requested soft tissue lateral neck x-rays are measured and compared to the standards published in the Atlas of Roentgenographic Measurement by Keats and Lusted which adopted a 1939 study by Hay et al. ${ }^{1}$ The Department of Otorhinolaryngology Head and Neck Surgery however uses criteria contained in the Textbook of Otorhinolaryngology Head and Neck Surgery by Cummings et al. ${ }^{2,3}$ In fact, within this textbook are three (3) standards: the first by Duncan on the chapter on Infections of the Airway ${ }^{2}$ and the second and third by Wippold in the chapter on Diagnostic Imaging of the Larynx. ${ }^{3}$ This difference in standards often poses problems for practitioners making their resolution significant in the management of patients. This study aims to determine the prevertebral soft tissue thickness among normal patients aged 0-14 years old in our institution, to compare these values with divergent criteria in the standard otorhinolaryngology and radiology texts used in our institution, and to recommend adoption of a set of criteria based on the results.

\section{METHODS}

Lateral cervical radiographs initially read as normal from patients aged 0-14 years old from May 2007 to August 2009 were retrospectively reviewed. Only radiographs of patients taken in neutral neck position with no history of head and neck infection, intubation, nasogastric tube insertion and congenital or acquired abnormality of the cervical spine were included. All patients were confirmed trauma or child abuse cases and their radiographs had been taken within 24 hours of the injury for medicolegal clearance.

The x-ray machines used were 1000mA Hitachi Trophy N800 and Hitachi Trophy N500 (Hitachi Corporation, Japan) with the following settings: tube current (mAs) 2-2.5, tube voltage $(\mathrm{kVp})$ dependent on patient's thickness. Magnification was disregarded.

Individual measurements of all radiographs were independently performed in separate venues over different time periods by the four authors: two from the Department of Otorhinolaryngology and two from the Department of Medical Imaging using two vernier calipers. The prevertebral soft tissue widths and vertebral body diameter at levels C2, C5, C7 were measured to the nearest hundredths of a millimeter using a vernier caliper (Figure 1). It was measured from the most anterior and inferior aspect of the adjacent cervical vertebral body up to the posterior pharyngeal wall. Figure 2 illustrates the schematic diagram of the prevertebral soft tissue thickness at each vertebral level. Data obtained were tabulated and averaged using a Microsoft Excel

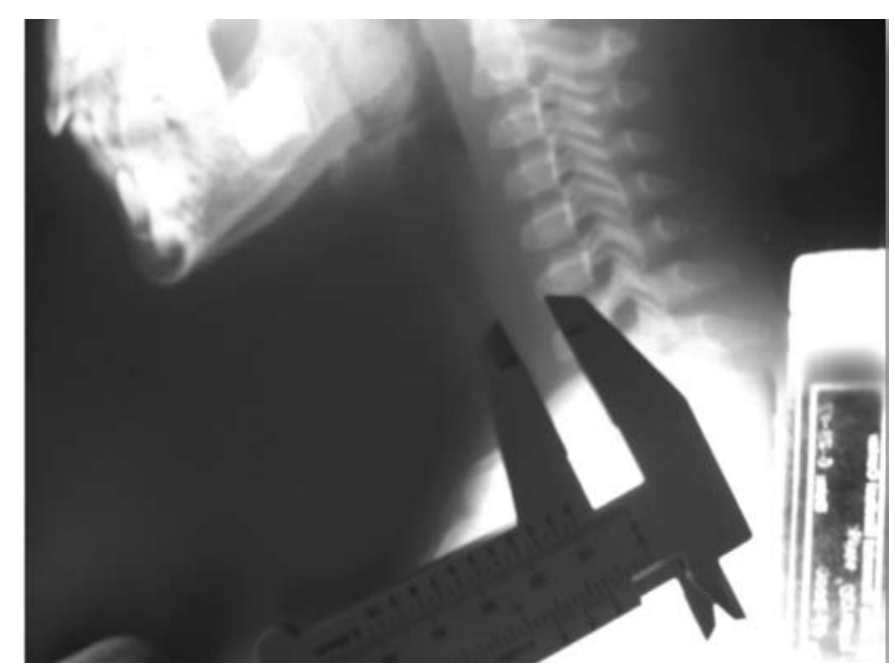

Figure 1. Prevertebral soft tissue thickness measurement using a Vernier caliper

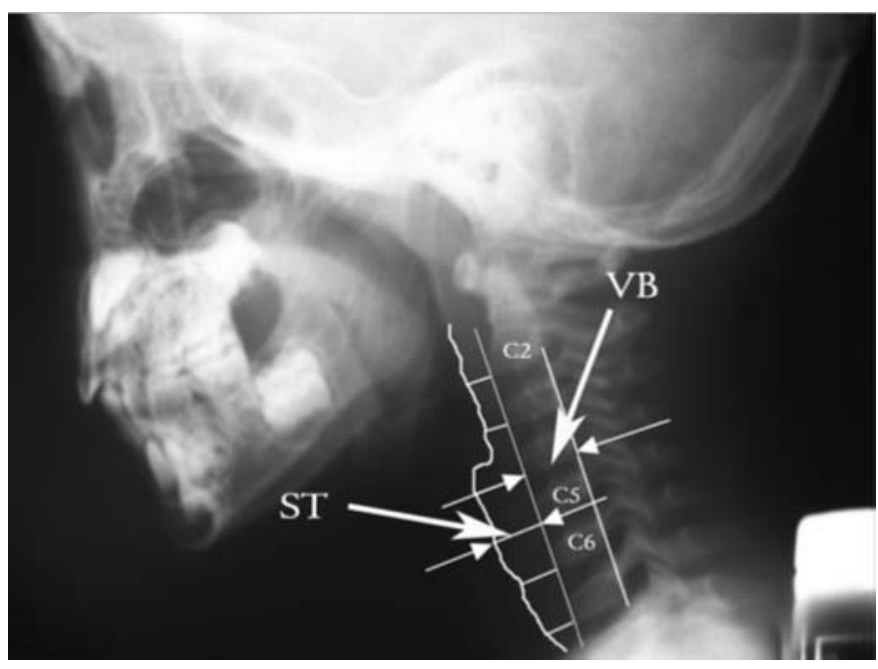

Figure 2. Actual lines of Measurement for PVST. VB (Vertebral Body), ST (Prevertebral Soft Tissue)

2010 file (Microsoft Corporation, Redmond, WA, USA) rounded to the nearest hundredths place. The ranges, mean and standard deviations were determined.

Age stratification was adapted from Keats and Lusted ${ }^{1}$ for validation purposes and to account for the physical changes during growth and development. The data was then compared to the four traditionally used criteria- the first from Keats and Lusted (Table 1) and the second, third and fourth from Cummings.

\section{RESULTS}

There were 50 radiographs of patients included in the study. Thirtynine (39) or $78 \%$ were male and 11 or $22 \%$ were female. Table 2 shows the age distribution of the patients.

Tables 3 to 5 show the range of prevertebral soft tissue and vertebral 
ORIGINAL ARTICLES

Table 1. Upper normal limits of the Soft Tissue Spaces of the Neck (Keats)

\begin{tabular}{|c|c|c|c|c|}
\hline AGE RANGE & \multicolumn{2}{|c|}{ Post Pharyngeal Soft Tissue } & \multicolumn{2}{|c|}{ Postventricular Soft Tissue } \\
\hline $0-1$ & \multicolumn{2}{|c|}{$1.5 C 5$} & \multicolumn{2}{|c|}{$2.0 C 5$} \\
\hline $1-2$ & \multicolumn{2}{|c|}{$0.5 C 5$} & \multicolumn{2}{|c|}{$1.5 C 5$} \\
\hline $2-3$ & \multicolumn{2}{|c|}{$0.5 C 5$} & \multicolumn{2}{|c|}{1.265} \\
\hline $3-6$ & \multicolumn{2}{|c|}{$0.4 C 5$} & \multicolumn{2}{|c|}{1.265} \\
\hline $6-14$ & \multicolumn{2}{|c|}{$0.3 C 5$} & \multicolumn{2}{|c|}{1.265} \\
\hline \multirow{3}{*}{ ADULT } & & & \multicolumn{2}{|c|}{ Postcricoid } \\
\hline & Male & Female & Male & Female \\
\hline & 0.365 & 0.365 & $0.7 C 5$ & $0.6 C 5$ \\
\hline
\end{tabular}

Table 2. Age Distribution of Patients

\begin{tabular}{c|c|c|}
\hline AGE RANGE & FREQUENCY & PERCENTAGE (\%) \\
\hline $0-1$ & 3 & $6 \%$ \\
\hline $1-2$ & 2 & $4 \%$ \\
\hline $2-3$ & 2 & $4 \%$ \\
\hline $3-6$ & 12 & $24 \%$ \\
\hline $6-14$ & 31 & $62 \%$ \\
\hline Total & 50 & $100 \%$ \\
\hline
\end{tabular}

Table 3. Range of Prevertebral Soft Tissue and Vertebral Body Diameters at Level C2

\begin{tabular}{c|c|c|} 
AGE RANGE & $\begin{array}{c}\text { PREVERTEBRAL SOFT TISSUE } \\
\text { RANGE }(\mathbf{m m})\end{array}$ & VERTEBRAL BODY RANGE (mm) \\
\hline $0-1$ & $4.53-10.45$ & $5.54-8.38$ \\
\hline $1-2$ & $4.13-12.20$ & $9.29-9.60$ \\
\hline $2-3$ & $3.73-4.31$ & $9.23-9.35$ \\
\hline $3-6$ & $3.71-6.64$ & $8.90-13.23$ \\
\hline $6-14$ & $3.73-7.68$ & $11.63-20.63$ \\
\hline
\end{tabular}

Table 4. Range of Prevertebral Soft Tissue and Vertebral Body Diameters at Level C5

\begin{tabular}{c|c|c|} 
AGE RANGE & $\begin{array}{c}\text { PREVERTEBRAL SOFT TISSUE } \\
\text { RANGE }(\mathbf{m m})\end{array}$ & VERTEBRAL BODY RANGE (mm) \\
\hline $0-1$ & $9.18-12.60$ & $6.16-9.73$ \\
\hline $1-2$ & $6.55-9.68$ & $10.14-11.00$ \\
\hline $2-3$ & $7.86-13.18$ & $9.50-10.60$ \\
\hline $3-6$ & $4.45-13.38$ & $8.43-12.69$ \\
\hline $6-14$ & $7.86-16.03$ & $11.38-21.78$ \\
\hline
\end{tabular}

Table 5. Range of Prevertebral Soft Tissue and Vertebral Body Diameters at Level C6

\begin{tabular}{c|c|c|} 
AGE RANGE & $\begin{array}{c}\text { PREVERTEBRAL SOFT TISSUE } \\
\text { RANGE (mm) }\end{array}$ & VERTEBRAL BODY RANGE (mm) \\
\hline $0-1$ & $7.74-13.03$ & $6.70-10.95$ \\
\hline $1-2$ & $4.70-9.55$ & $10.80-11.10$ \\
\hline $2-3$ & $9.18-10.63$ & $9.86-11.26$ \\
\hline $3-6$ & $3.84-10.23$ & $9.35-13.94$ \\
\hline $6-14$ & $6.10-14.18$ & $11.13-23.31$ \\
\hline
\end{tabular}

body diameters at levels C2, C5 and C6. The means and standard deviations of the prevertebral soft tissue thickness and vertebral body diameters of $\mathrm{C} 2, \mathrm{C} 5, \mathrm{C} 6$ are summarized according to age groups in Tables 6 to 8 .

The data collected was validated using the formula suggested by Keats and Lusted ${ }^{1}$ wherein the $C_{5}$ vertebral body diameter was used as reference. Of the 50 radiographs reviewed, 44 (88\%) patients were above normal limits and only $6(12 \%)$ patients satisfied the criteria. Using Duncan's criteria all patients were within normal limits. On the other hand, using Wippold's $1^{\text {st }}$ criteria at C2 level, 47(94\%) patients were within normal limits while 3 patients were above normal limits. At C6 level, 49 (98\%) satisfied the criteria while only 1 (2\%) did not. Table 9 shows the summary of patients who passed and failed using Keats' and Cummings' Standards.

\section{DISCUSSION}

Since 1939, prevertebral soft tissue measurement has been commonly used for assessing prevertebral pathology such as abscesses or hematomas after injury. ${ }^{2}$ Radiographs, particularly soft tissue lateral cervical roentgenograms are often requested for evaluation. Compared with computed tomography, lateral cervical neck films are about 83\% sensitive in children. Extremes of neck extension or flexion can produce misleading findings as can films taken during forced inhalation.

The first step in the algorithm followed in our institution in diagnosing deep neck infections in pediatric patients includes a neck soft tissue lateral x-ray in neutral position. Although computed tomography is readily available and can provide more information on the extent of infection, it is still costly and harder to perform in children especially if serial imaging is needed to monitor disease progression. Children often have to be sedated since they must remain still for a few minutes compared to a few seconds when taking an x-ray.

In the evaluation of PVST, otorhinolaryngologists in our institution use criteria contained in Cummings' Textbook of Otolaryngology Head and Neck Surgery. ${ }^{2,3}$ The three sets of criteria contained therein have sparked debate as to which should be used. The first (by Duncan) stating that the PVST at C2 should not exceed twice the diameter of the C2 vertebral body cited a 1991 study by Coulthard. ${ }^{4}$ However, this was a review of the management of retropharyngeal abscesses and not a study to actually derive such a formula. In another chapter, Wippold mentioned two standards and cited a 1995 study by Pontell ${ }^{5}$ which suggested that the prevertebral soft tissue should not exceed $7 \mathrm{~mm}$ measured from the most anterior aspect of C2 to the posterior pharyngeal wall and at $C 6$, the thickness of the retropharyngeal tissues should not be $>14 \mathrm{~mm}$ in children and $22 \mathrm{~mm}$ in adults. Again, Pontell's study was a case series of 20 patients with retropharyngeal abscess. 


\section{ORIGINAL ARTICLES}

Table 6. Mean and Standard Deviation $(\mathrm{mm})$ of the Prevertebral Soft Tissue and Vertebral Body Diameter at level $C 2$

\begin{tabular}{l|c|c|c|c|c}
\multirow{2}{*}{ Age } & \multirow{2}{*}{$\begin{array}{c}\text { Pop* } \\
(\mathbf{n = 5 0 )}\end{array}$} & \multicolumn{4}{|c}{$\mathbf{2}^{* *}$} \\
\cline { 3 - 6 } & 3 & mean & SD & mean & SD \\
\cline { 3 - 6 } & 2 & 8.25 & \pm 2.99 & 6.60 & \pm 1.55 \\
\hline $0-1$ & 2 & 4.02 & \pm 0.42 & 9.29 & \pm 0.08 \\
\hline $1-2$ & 12 & 5.18 & \pm 1.14 & 11.44 & \pm 1.47 \\
\hline $2-3$ & 31 & 5.49 & \pm 1.36 & 19.81 & \pm 2.53 \\
$3-6$ & & & & \\
\hline $6-14$ & & & & \\
\hline
\end{tabular}

Table 7. Mean and Standard Deviation ( $\mathrm{mm}$ ) of the Prevertebral Soft Tissue and Vertebral Body Diameter at level C5

\begin{tabular}{c|c|c|c|c|c}
\multirow{2}{*}{ Age } & \multirow{2}{*}{$\begin{array}{c}\text { Pop } \\
(\mathbf{n}=50)\end{array}$} & \multicolumn{3}{|c|}{ ST } & \multicolumn{2}{|c}{ VB } \\
\cline { 3 - 6 } & 3 & mean & SD & mean & SD \\
\hline $0-1$ & 2 & 8.11 & \pm 2.21 & 10.57 & \pm 0.61 \\
\hline $1-2$ & 2 & 10.52 & \pm 3.76 & 10.05 & \pm 0.78 \\
\hline $2-3$ & 12 & 8.12 & \pm 2.47 & 11.20 & \pm 1.35 \\
\hline $3-6$ & 31 & 10.67 & \pm 1.57 & 16.40 & \pm 2.51 \\
\hline $6-14$ & & & & &
\end{tabular}

Table 8. Mean and Standard Deviation $(\mathrm{mm})$ of the Prevertebral Soft Tissue and Vertebral Body Diameter at level C6

\begin{tabular}{c|c|c|c|c|c}
\multirow{2}{*}{ Age } & \multirow{2}{*}{$\begin{array}{c}\text { Pop } \\
(\mathbf{n = 5 0 )}\end{array}$} & \multicolumn{3}{|c|}{ ST } & \multicolumn{2}{|c}{ VB } \\
\cline { 3 - 6 } & & mean & SD & mean & SD \\
\hline $0-1$ & 3 & 10.36 & \pm 2.64 & 8.25 & \pm 2.35 \\
\hline $1-2$ & 2 & 7.13 & \pm 3.43 & 10.95 & \pm 0.21 \\
\hline $2-3$ & 2 & 9.90 & \pm 1.02 & 10.56 & \pm 0.99 \\
$3-6$ & 12 & 7.59 & \pm 1.89 & 11.90 & \pm 1.26 \\
\hline $6-14$ & 31 & 9.99 & \pm 1.91 & 17.63 & \pm 2.80 \\
\hline
\end{tabular}

Table 9. Number of Patients ( $n=50$ ) who passed and failed using Keats' Standard, and Cummings' Standards

\begin{tabular}{|c|c|c|c|c|c|c|c|c|}
\hline \multirow{4}{*}{ Age } & \multirow{3}{*}{\multicolumn{2}{|c|}{ Keats etal }} & \multicolumn{6}{|c|}{ Cummings et.al. } \\
\hline & & & \multicolumn{4}{|c|}{ Wippold } & \multirow{2}{*}{\multicolumn{2}{|c|}{$\begin{array}{c}\text { Duncan } \\
\text { PVST } \leq 2 \mathrm{C} 2\end{array}$}} \\
\hline & & & \multicolumn{2}{|c|}{$\begin{array}{l}\text { PVST } \leq 7 \mathrm{~mm} \\
\text { At C } 2 \text { level }\end{array}$} & \multicolumn{2}{|c|}{$\begin{array}{c}\text { PVST } \leq 14 \mathrm{~mm} \\
\text { At C6 level }\end{array}$} & & \\
\hline & Pass* & Fail $^{* *}$ & Pass & Fail & Pass & Fail & Pass & Fail \\
\hline $0-1$ & 3 & 0 & 2 & 1 & 3 & 0 & 3 & 0 \\
\hline $1-2$ & 2 & 0 & 1 & 1 & 2 & 0 & 2 & 0 \\
\hline $2-3$ & 0 & 2 & 2 & 0 & 2 & 0 & 2 & 0 \\
\hline $3-6$ & 1 & 11 & 12 & 0 & 12 & 0 & 12 & 0 \\
\hline $6-14$ & 0 & 31 & 30 & 1 & 30 & 1 & 31 & 0 \\
\hline Total & 6 & 44 & 47 & 3 & 49 & 1 & 50 & 0 \\
\hline$\%$ & $12 \%$ & $88 \%$ & $94 \%$ & $6 \%$ & $98 \%$ & $2 \%$ & $100 \%$ & $0 \%$ \\
\hline
\end{tabular}

*Pass $=$ within normal limits

**Fail= above normal limits
These formulas were used and validated but were not actually set or determined in that study.

From the time our hospital was established, the Department of Medical Imaging has been using Keats and Lusted as a reference for the evaluation of PVST, citing a formula derived by Hay in 1939 to compute normal prevertebral soft tissue at certain age levels. The formula was derived from a sample of 25 pediatric and 50 adult normal patients.' Age stratification was used for pediatric patients but only up to 14 years of age. For purposes of validation, we adopted this age stratification for this study.

Several studies have focused on the radiographic evaluation of prevertebral soft tissues in adults. Chen et al. in 1999 stated that the maximum retrocricoid soft tissue thickness was $0.7 \times \mathrm{C} 5$ diameter and that the maximum retrotracheal thickness was $1.0 \times$ C5 diameter. ${ }^{6}$ Sistrom and colleagues in 1993 identified factors affecting cervical soft tissue thickness by measuring the soft tissues anterior to $\mathrm{C} 2$ through $\mathrm{C} 4$ in lateral cervical spine films of 227 patients examined over two years.? These measurements were correlated with patient age, sex, weight, shoulder width, neck width and calculated radiographic magnification. They found that only patient weight and age had a statistically significant correlation with soft tissue thickness. Using a stepwise regression model they produced a simple equation for predicting the mean value of the soft tissue thickness at $\mathrm{C} 3$ based on the patient's age and weight, and determined that weight and age account for $28 \%$ of the observed variability in the soft tissue measurements at $\mathrm{C} 3$. These relationships were similar at $\mathrm{C} 2$ and $\mathrm{C} 4$.

The study by Haug, et al., ${ }^{8}$ of 86 normal lateral soft-tissue radiographs reported that the mean thickness in the retropharyngeal region ranged from $6.2 \mathrm{~mm}$ in the infant to $3.7 \mathrm{~mm}$ in the adult while the mean thickness in the retrotracheal region ranged from $9.2 \mathrm{~mm}$ in the preschool group to $12.1 \mathrm{~mm}$ in the adult. This study was cited by Craig and colleages as their reference for normal values in their study on retropharyngeal acesses in children. ${ }^{9}$

Another study by Chi measured the PVST from C1 to C7 in 150 Chinese patients and compared values with western populations from previous studies. They found significant differences in PVST between young $(n=106)$ and older $(n=25)$ subjects and between males $(n=52)$ and females ( $n=79$ ) at $C 6$, concluding that PVST was thicker in males and the elderly compared to females and younger subjects. There was no difference between their data and values from the western studies. ${ }^{10}$

Studies on normal prevertebral soft tissue measurements often involve adults. ${ }^{6,7,8,10}$ An obvious reason for the very limited number of studies in pediatric patients is the ethical issue of subjecting normal children to radiation. 
Recent studies recommend the use of computed tomography instead of traditional radiographs since CT scan can differentiate more accurately between retropharyngeal absess and cellulitis, both of which cause prevertebral soft tissue thickening but have different management. ${ }^{9}$ However, our institution still utilizes less expensive radiographs. Our study utilized radiographs of medicolegal trauma cases taken within 24 hours of injury and initially read as normal, minimizing the chances of soft tissue swelling. Frank cervical vertebra injuries and soft tissue hematomas would have been clinically and radiographically evident within 24 hours and were excluded. Further, all 50 patients whose radiographs were included in our study had been apparently well and discharged from the emergency room.

Only $12 \%$ of the patients satisfied the criteria set by Keats and Lusted while $100 \%$ satisfied Duncan's criteria, $94 \%$ and $98 \%$ satisfied Wippold's first and second criteria, respectively. All of the criteria mentioned in Cummings' Textbook of Otorhinolaryngology Head and Neck Surgery had a more than $90 \%$ accuracy compared to only $12 \%$ for those mentioned in Keats and Lusted's Atlas of Roentgenographic Measurement. Persisting in using the latter criteria would result in more of the PVST being read as abnormal and subsequent over-treatment. Therefore, we recommend the use of any criteria for PVST contained in the former over the latter.

In light of the results of this study, we recommend that future studies reevaluate the previously "abnormal" readings excluded from this study, to find out how many of them would actually be false positives (with no actual prevertebral soft tissue thickening based on Cummings' criteria), possibly resulting in over-treatment with prolonged antibiotics and/or tracheotomy.

\section{REFERENCES}

1. Keats TE, Lusted LB. Atlas of Roentgeongraphic Measurement $4^{\text {th }}$ ed, Year Book Medical Publishers Inc. 1981.

2. Duncan NO. Infections of the Airway. In: Cummings C, Flint PW, Harker LA, Haughey BH, Richardson, MA, Robbins KT, et.al., editors. Cummings C. Otorhinolaryngology Head and Neck Surgery $4^{\text {th }}$ ed Philadelphia: Elsevier Mosby; 2005. Chapter 195.

3. Wippold FJ. Diagnostic Imaging of the Larynx. In: Cummings C, Flint PW, Harker LA, Haughey $\mathrm{BH}$, Richardson, MA, Robbins KT, et.al., editors. Cummings C. Otorhinolaryngology Head and Neck Surgery $4^{\text {th }}$ ed. Philadelphia: Elsevier Mosby; 2005. Chapter 88.

4. Coulthard M, Isaacs D. Retropharyngeal abscess. Archives of Disease in Childhood 1991; 66: 12271230.

5. Pontell J, Har-El G, Lucente F. Retropharyngeal abscess: clinical review. Ear Nose Throat J. 1995 Oct; 74(10):701-4.

6. Chen MY, Bohrer SP. Radiographic measurement of prevertebral soft tissue thickness on lateral radiographs of the neck. Skeletal Radiol.1999 Aug; 28(8): 444-6.

7. Sistrom CL, Southall EP, Peddada SD, Shaffer HA Jr. Factors affecting the thickness of the cervical prevertebral soft tissues. Skeletal Radiol. 1993; 22(3):167-71.

8. Haug RH, Wible RT, Lieberman J. Measurement standards for the prevertebral region in the lateral soft-tissue radiograph of the neck. J Oral Maxillofac Surg. 1991 Nov; 49(11):1149-51.

9. Craig FW, Schunk JE. Retropharyngeal abscess in children: clinical presentation, utility of imaging and current management. Pediatrics 2003;111:1394-1398.

10. Chi LJ, Wang ADJ, Chen LK. Prevertebral Soft Tissue Measurements on Lateral Roentgenogram of Cervical Spine in Chinese. Chin J Radiology. 2002; 27:151-155. 